\section{A metrópole como obra de arte}

Heloisa PONTES. Intérpretes da metrópole: história social e relações de gênero no teatro e no campo intelectual, 1940-1968. São Paulo, Edusp, 2010. 464 páginas. [prêmio "Melhor Obra Científica" atribuída pelo "Concurso Brasileiro Anpocs de obras científicas e teses universitárias em Ciências Sociais - edição 2011.]

\section{Ricardo Benzaquen de Araujo}

Intérpretes da metrópole é construído em função de uma intenção básica, qual seja, a de examinar os vínculos que podem ser estabelecidos entre o processo de metropolização que ocorre em São Paulo entre 1940 e 1968 e as variadas transformações que podem ser percebidas, nesse período, no seu ambiente cultural. Não imagine o leitor, porém, que estamos aqui diante de uma narrativa sintética e totalizante, obcecada em elaborar um quadro dotado de um ponto central que desse sentido ao conjunto das questões sob investigação.

Ao contrário, o que salta aos olhos à medida que se percorre este magnífico trabalho é a preocupação em qualificar, de maneira cuidadosa e delicada, tanto os temas como os argumentos em debate, o que levou à divisão do texto em duas partes: a primeira concentra-se em uma dimensão propriamente intelectual, analisando o grupo de jovens que se reunia em torno da revista Clima, como por exemplo Antonio Candido, Décio de Almeida Prado e Gilda Melo e Souza, e suas relaçōes com a Universidade de São Paulo, que começava então a se afirmar como um dos líderes na implantação de uma cultura acadêmica no país; a segunda, por sua vez, dedica-se à análise do surgimento e da consolidação do Teatro Brasileiro de Comédia (TBC), palco que criará condições para uma profunda reformulação da atividade dramática entre nós; ambos os cenários, cabe enfatizar, avaliados de um ângulo que privilegia o esclarecimento das relaçôes de gênero, mais especificamente do papel desempenhado pelas mulheres no ambiente animado por essas duas instituições.

Os dois primeiros capítulos, diretamente envolvidos com a vida intelectual, têm como ponto de partida uma comparação entre Clima e a Partisan
Review, de Nova York, aproximando as duas publicaçôes quer pela seriedade acadêmica que norteia seus artigos quer por sua abertura para as questôes típicas das metrópoles que as circundam. Por outro lado, torna-se evidente a diferença no tratamento dispensado às mulheres, inclusive pela maior liberalidade, no plano dos costumes, que caracterizava o periódico norte-americano. A questão da condição feminina, aliás, será retomada no segundo capítulo pelo exame das trajetórias de Lucia Miguel Pereira, Patrícia Galvão (Pagu) e Gilda Mello e Souza, intelectuais que pagaram um preço dos mais altos pela sua busca da dignidade profissional.

Do capítulo 3 em diante, Heloisa Pontes detém-se em uma minuciosa pesquisa acerca das modificações estéticas e sociais que tornaram possível a concretização de um projeto como o do TBC. Assim, podemos acompanhar, por exemplo, o impacto produzido pela passagem no Brasil da companhia francesa de Louis Jouvet, fundamental para a instauração de um novo entendimento da experiência dramática, no qual, contra as audiçōes mambembes, de "Boulevard", repletas de "pontos", "cacos" e baseadas na absoluta centralidade da figura do protagonista, salienta-se a importância da integração entre autor, diretor e ator, numa perspectiva sistemática que parece realçar, em vez de restringir, o destaque concedido ao talento das grandes atrizes da época, como Maria Della Costa, Cleyde Yáconis e, sobretudo, Cacilda Becker. E mais, esse destaque seria incompreensível se não se levasse em consideração o interesse de empresários como Franco Zampari e Alfredo Mesquita na modernização da vida cultural de São Paulo, nem o despontar de uma articulação, quase inédita, entre a crônica jornalística e o ensinamento universitário, demonstrada de forma cabal por um crítico e historiador do porte de Décio de Almeida Prado. Além disso, não se deve esquecer da atuação de um número significativo de parceiros - amorosos ou não -, com freqüência ligados àquele mesmo universo, na sustentação das suas carreiras. Não é à toa, portanto, que tenha se constituído por esta época um contexto capaz de permitir que mesmo atrizes oriundas de camadas "humildes" da população, como as mencionadas acima, tenham atingido um sucesso profissional e brilho pessoal de enorme 
intensidade.

Este conjunto de argumentos exige que se faça uma breve pausa no sentido de investigar mais detidamente o próprio significado conferido pela autora à ideia de metrópole. Parece que Heloisa opera com uma concepção bem distante daquela que associa o cotidiano das grandes cidades modernas ao que se convencionou chamar, na esteira de G. Simmel e W. Benjamin, de "experiência de choque". Nesta visão, o caráter inesperado e veloz dos múltiplos estímulos que se precipitam simultaneamente sobre os habitantes destas grandes cidades termina por desorientá-los, embaralhando seus critérios de valor e desfigurando o mapa cognitivo que guiava suas condutas. Intérpretes da metrópole, contudo, lida com o assunto de modo diverso, apontando para uma direção na qual São Paulo emerge como um lugar de encontros improváveis, onde, repita-se, mulheres marcadas pelo desencanto, pela privação e pelos estigmas associados ao gênero têm acesso à oportunidade de se reinventar por intermédio, por exemplo, do teatro.

A sociabilidade cultivada em torno do tbc, ao menos no que se refere à sua capacidade de atenuar estas marcas, transmite a sensação de ser mais efetiva do que a própria experiência universitária. Basta comparar, para tanto, a carreira de Gilda Mello e Souza com a de Cacilda Becker: na revista Clima, embora tenha sido aceita como uma colaboradora regular, o lugar designado para Gilda é o da literatura de ficção, modalidade supostamente mais compatível com a condição feminina. Heloisa Pontes conta que, até para combater o estereótipo, Gilda passa a frequentar o gênero do ensaio, entre a filosofia e as ciências sociais. Esta decisão, todavia, consegue apenas adiar, mas não eliminar o problema, que será reencontrado mais adiante, na USP, por ocasião da defesa de sua tese de doutorado sobre a moda no século XIX, aprovada mas considerada, "à boca pequena", fútil e pouco importante. Em suma: coisa de mulher. Cacilda, como já sugerido, segue outra rota, convertendo sua atuação no tbc em uma espécie de rito de passagem que lhe permitirá reescrever a própria biografia e passar, de menina pobre e excluída, uma estranha na cidade, à condição de maior estrela do teatro brasileiro.

Como se pode dar conta dessa diferença? A resposta, creio, é apresentada logo nas primeiras páginas da introdução de Intérpretes da Metrópole, quando Heloisa chama a atenção para os distintos registros em que se deve inscrever a performance das atrizes de cinema em relação às de teatro. As primeiras, com efeito, parecem representar sempre a si mesmas, ou melhor, a uma espécie de persona que se constrói em torno delas, enquanto as segundas, assumindo integralmente as características específicas das suas personagens, modificam-se a cada apresentação.

Ora, se associarmos a este argumento o fato de que as encenações sempre se dão ao vivo, sob contingências até certo ponto imprevisíveis e que precisam ser superadas dia a dia para que o espetáculo chegue a bom termo, torna-se evidente que o desempenho, em toda a sua fragilidade e grandeza, parece se constituir no traço peculiar dessas grandes profissionais de teatro. É como se fosse necessário dispor de capacidade suficiente para matar um leão por dia, justamente a característica que, segundo Max Weber, definirá o que ele chama de autoridade carismática.

De fato, correndo o risco de se metamorfosear regularmente em diferentes identidades e de sustentar seus papéis em qualquer situação, essas atrizes de teatro mostram-se capazes de desafiar cotidianamente chuvas e trovoadas, dando a cara ao tapa em função de uma performance que, se condensa uma série de determinações prévias, depende, no momento preciso da encenação, da afirmação do seu talento. Dotadas de um carisma relativamente maior do que aquele que suas equivalentes universitárias pareciam ostentar, elas talvez encontrem, por este caminho, uma primeira explicação para a superação parcial dos constrangimentos de gênero que, mesmo de forma desigual, ainda persistiam na metrópole.

Muito mais poderia ser dito sobre este belo trabalho de Heloisa Pontes, mas isto não caberia nos limites de uma resenha. Para encerrar, vale à pena sublinhar que, atuando de maneira criativa entre a etnografia e o ensaio, sempre preocupada em resgatar a complexidade e a dignidade intelectual das questôes sob exame, a autora surge aqui como uma intérprete autorizada daquelas intérpretes da metrópole. Mais do que um pueril jogo de palavras, esta observação pode até permitir que o caráter quase 
luxuoso da edição - capa dura, papel couché, rica iconografia, generoso espaço concedido às margens das páginas, enfim, notável projeto gráfico -, aliado à forma elegante, primorosa mesmo, em que o texto é redigido, deixe de ser uma mera casualidade: o livro, como objeto, converte-se em uma espécie de novo TBC, um TBC de bolso, cuja visita certamente contribuirá para uma melhor compreensão daquela grande aventura intelectual e estética.

RICARDO BENZAQUEN DE ARAUJO é professor da Puc-Rio e do Iesp-Uerj. E-mail: <rbenzaquen@iesp.uerj.br>.

\section{Fronteiras da laicidade}

Jean BAUBÉROT \& Micheline MILOT. Lä̈cités sans frontières. Paris, Seuil, 2011. 349 páginas.

\section{Emerson Giumbelli}

O livro dos sociólogos Jean Baubérot e Micheline Milot se tornará provavelmente uma referência incontornável no tema a que se dedica. A obra dá continuidade a discussões que cada um deles vem realizando a partir de posições acadêmicas importantes, ele na França, ela no Canadá. Vers un noveau pacte lä̈que?, de 1990, talvez seja o marco inaugural da conexão de Baubérot com o tema, ao qual Milot se junta alguns anos depois. Além disso, ambos são referências cruciais para a Rede Iberoamericana Liberdades Laicas, presente também no Brasil com a realização de eventos, publicações e posicionamentos públicos. Na América Latina, Liberdades Laicas é a divulgadora da "Declaração Universal sobre a Laicidade no Século XXI", que Baubérot e Milot ajudaram a elaborar. Sua atuação tem se feito sentir em debates envolvendo assuntos como o reconhecimento de direitos sexuais e reprodutivos, a retirada de símbolos religiosos de recintos estatais, o questionamento do ensino religioso em escolas públicas etc.

Apontar para a circulação dos autores e suas ideias em empreendimentos ativistas pode levar, cedo demais, a uma desconfiança sobre os objetivos declarados do livro, uma vez que ele se apresenta como um exercício sociológico que pretende se distanciar dos "usos sociais" de seu tema. Nessa linha, visa fundamentar a laicidade como conceito analítico que permitiria caracterizar, no plano empírico, as laicidades, ou seja, distintas configuraçōes estabelecidas em espaços nacionais e momentos históricos. Seis partes compõem o livro. Na primeira, elabora-se uma genealogia da laicidade, destacando a política inglesa no século XVII, o ideário de algumas seitas protestantes, e certos marcos filosóficos, sobretudo as elaborações de John Locke (1632-1704) sobre a tolerância. Na segunda, propõe-se uma definição da laicidade, a partir da qual se delineiam seis tipos ideais para identificar suas possíveis configuraçôes. Em seguida, os autores posicionam-se diante das alternativas que, em um debate intelectual, sua definição da laicidade 